\title{
Can glass stability parameters infer glass forming ability?
}

\author{
Marcio L.F. Nascimento, Luciana A. Souza, Eduardo B. Ferreira, \\ Edgar D. Zanotto * \\ Vitreous Materials Laboratory, Department of Materials Engineering, Federal University of São Carlos, \\ 13565-905 São Carlos, SP, Brazil
}

Received 18 July 2005

\begin{abstract}
Glass-forming ability (GFA) is the easiness to vitrify a liquid on cooling, while glass stability (GS) is the glass resistance against devitrification on heating; but it is questionable if there is any direct relationship between these two parameters. Therefore, to test this possibility, we assess and compare GFA and several GS parameters through quantitative criteria. GFA and GS were calculated for six stoichiometric glass forming oxides that only present surface (heterogeneous) crystallization in laboratory time scales: $\mathrm{GeO}_{2}, \mathrm{Na}_{2} \mathrm{O}$. $2 \mathrm{SiO}_{2}, \mathrm{PbO} \cdot \mathrm{SiO}_{2}, \mathrm{CaO} \cdot \mathrm{Al}_{2} \mathrm{O}_{3} \cdot 2 \mathrm{SiO}_{2}, \mathrm{CaO} \cdot \mathrm{MgO} \cdot 2 \mathrm{SiO}_{2}$ and $2 \mathrm{MgO} \cdot 2 \mathrm{Al}_{2} \mathrm{O}_{3} \cdot 5 \mathrm{SiO}_{2} ;$ plus $\mathrm{Li}_{2} \mathrm{O} \cdot 2 \mathrm{SiO}_{2}$ and $\mathrm{Li}_{2} \mathrm{O} \cdot 2 \mathrm{~B}_{2} \mathrm{O}_{3}$ that, in addition to surface nucleation, also present homogeneous (internal) crystallization. We gauge GFA by the critical cooling rate, $q_{\mathrm{cr}}$, which was calculated from an estimated number of heterogeneous nucleation sites per unit surface, $N_{\mathrm{s}}$, and from experimental crystal growth rates, $u(T)$, assuming a detectable surface crystallized fraction $X_{\mathrm{c}}=0.001$. We define GS parameters by fourteen different combinations of the following characteristic differential thermal analysis (DTA) or differential scanning calorimetry (DSC) temperatures: the glass transition temperature $\left(T_{\mathrm{g}}\right)$, the onset crystallization temperature on heating $\left(T_{x}^{\mathrm{h}}\right)$, the peak crystallization temperature on heating $\left(T_{\mathrm{c}}^{\mathrm{h}}\right)$, and the melting point $\left(T_{\mathrm{m}}\right)$. To obtain the experimental GS parameters for each glass we carried out DSC runs using coarse and fine powders, and completed the necessary data with literature values for $T_{\mathrm{m}}$. The results for fine and coarse particles were quite similar. Most of the GS parameters that consist of three characteristic DSC temperatures show excellent correlation with GFA, however, rather poor correlations were observed for parameters that use only two characteristic temperatures. We thus demonstrated that certain, but not all GS parameters can be used to infer GFA.
\end{abstract}

(C) 2005 Elsevier B.V. All rights reserved.

PACS: $64.70 . \mathrm{Dv} ;$ 81.10.Aj

\section{Introduction}

There is now consensus that any material can vitrify if cooled from the molten state to the glass transition temperature, $T_{\mathrm{g}}$, at a rate fast enough to prevent crystallization. The slowest a material can be cooled down to $T_{\mathrm{g}}$ without crystallization the easiest it is vitrified, and this property is denominated glass forming ability (GFA). A maximum allowed fraction of crystals, $X_{\mathrm{c}}$, usually taken between

\footnotetext{
* Corresponding author. Tel.: +55 16260 8527; fax: +55 162615404 .

E-mail address: dedz@power.ufscar.br (E.D. Zanotto).

$U R L$ : http://www.lamav.ufscar.br (E.D. Zanotto).
}

$0.1 \%$ and $0.0001 \%$, is conventionally assumed to classify a material as glassy. One can thus define a critical cooling rate, $q_{\mathrm{cr}}$, to avoid a crystalline fraction higher than $X_{\mathrm{c}}$ on cooling a liquid. Therefore, $q_{\mathrm{cr}}$ gauges GFA. However, it is quite difficult to accurately measure $q_{\mathrm{cr}}$ and the complexity increases for reluctant glass formers that require very high cooling rates. If one could devise indirect ways to estimate GFA would then avoid exhaustive laboratory investigations, and this is thus a key step for efficient development of new glasses and glass-ceramics.

On the other hand, once a glass is made, for instance by fast quenching a melt, its stability against crystallization can be easily investigated. The resistance of a given glass 
against crystallization upon reheating defines glass stability (GS). GS is typically derived from characteristic temperatures that are determined from simple non-isothermal analyses, such as DTA or DSC. It is thus desirable to know how one can estimate GFA from GS measurements. However, the definitions of GS are somewhat arbitrary, only seldom have been rigorously tested and, as we will summarize below, it is controversial if there is any straightforward relationship between GFA and GS.

In this work, we experimentally test the existence of possible correlations between precisely calculated critical cooling rates (GFA) and fourteen ways to characterize GS using DSC. We use eight stoichiometric glasses: $\mathrm{GeO}_{2}$ (G), $\mathrm{Na}_{2} \mathrm{O} \cdot 2 \mathrm{SiO}_{2}\left(\mathrm{NS}_{2}\right), \mathrm{CaO} \cdot \mathrm{MgO} \cdot 2 \mathrm{SiO}_{2}\left(\mathrm{CMS}_{2}\right), \mathrm{PbO} \cdot$ $\mathrm{SiO}_{2}$ (PS), $2 \mathrm{MgO} \cdot 2 \mathrm{Al}_{2} \mathrm{O}_{3} \cdot 5 \mathrm{SiO}_{2}\left(\mathrm{M}_{2} \mathrm{~A}_{2} \mathrm{~S}_{5}\right)$ and $\mathrm{CaO}$. $\mathrm{Al}_{2} \mathrm{O}_{3} \cdot 2 \mathrm{SiO}_{2}\left(\mathrm{CAS}_{2}\right)$, which only show heterogeneous (surface) nucleation; plus $\mathrm{Li}_{2} \mathrm{O} \cdot 2 \mathrm{SiO}_{2}\left(\mathrm{LS}_{2}\right)$ and $\mathrm{Li}_{2} \mathrm{O} \cdot 2 \mathrm{~B}_{2} \mathrm{O}_{3}$ $\left(\mathrm{LB}_{2}\right)$ that also show homogeneous (internal) nucleation in addition to predominant surface nucleation. Therefore, the paper's objective is to systematically verify possible relationships between GFA and GS parameters for glasses that crystallize via the most common nucleation mechanism, i.e. surface (heterogeneous) nucleation.

\subsection{Literature review}

\subsubsection{Glass forming ability}

A variety of theories have been proposed to understand why some systems easily vitrify while others do not $[1,2]$. Ultimately, a high glass forming ability is associated with slow crystallization rates. Uhlmann [3] was one of the first to use the concept of crystallization kinetics controlling glass formation. His method refers to TTT (time-temperature-transformation) diagrams, which are temperature versus time graphs showing curves that correspond to specified fractions of transformed phase. A curve in a TTT diagram shows how one can set a thermal treatment to achieve a given fraction of transformed phase. To vitrify a liquid by cooling, the crystallized fraction of interest is normally the smallest detectable, usually assumed to be $10^{-2}-10^{-6}$. A 'nose' arises in the TTT diagrams at a temperature $T_{\mathrm{n}}$ and time $t_{\mathrm{n}}$ where the rate of transformation is the fastest. According to the nose method, the critical cooling rate for glass formation, $q_{\mathrm{cr}}^{\mathrm{n}}$, is given by

$q_{\mathrm{cr}}^{\mathrm{n}}=\frac{T_{\mathrm{m}}-T_{\mathrm{n}}}{t_{\mathrm{n}}}$.

However, critical cooling rates calculated by the nose method are typically one order of magnitude greater than experimentally determined values [4]. Thus, this method can only be used to estimate relative critical cooling rates and to compare the glass forming ability of different materials.

It is quite laborious to experimentally build $T T T$ curves, and it is yet not possible to theoretically calculate such curves due to the lack of an accurate expression for the nucleation rates. It is also rather difficult to directly measure critical cooling rates. To circumvent this problem, Colmenero and Barandiarán [5] proposed an experimental method to easily estimate $q_{\text {cr }}$ by determining the crystallization temperatures when a liquid is cooled in a DTA or DSC equipment at different rates, $q$. Their method is here denominated $\mathrm{CB}$. These authors suggested that on cooling a liquid, $q$ is related to $\Delta T_{\mathrm{c}}^{\mathrm{c}}$ by

$\ln q=A-\frac{B}{\left(\Delta T_{\mathrm{c}}^{\mathrm{c}}\right)^{2}}$,

where $\Delta T_{\mathrm{c}}^{\mathrm{c}}=T_{\mathrm{m}}-T_{\mathrm{c}}^{\mathrm{c}}, T_{\mathrm{c}}^{\mathrm{c}}$ is the crystallization peak temperature on cooling, and $A$ and $B$ are empirical constants obtained from a straight line in $(\ln q)$ versus $1 /\left(\Delta T_{\mathrm{c}}^{\mathrm{c}}\right)^{2}$ plots. If $\Delta T_{\mathrm{c}}^{\mathrm{c}}$ is extrapolated to infinity (no crystallization), $q_{\mathrm{cr}}$ can be determined from the intercept, $A$, of the line with the $\ln q$ axis. The physical meaning of Eq. (2) can be realized if we rewrite it using the classical formula of Turnbull for the thermodynamic driving force: $\Delta G\left(T_{\mathrm{c}}^{\mathrm{c}}\right)=\Delta S_{\mathrm{m}} \Delta T_{\mathrm{c}}^{\mathrm{c}}$. Eq. (2) then becomes $\ln q=\ln q_{0}-\frac{B \Delta S_{\mathrm{m}}^{2}}{\Delta G\left(T_{\mathrm{c}}^{\mathrm{c}}\right)^{2}}$, where $q_{0}$ is a constant. Therefore, compositions having low $\Delta G\left(T_{\mathrm{c}}^{\mathrm{c}}\right)$ and high melting entropy, $\Delta S_{\mathrm{m}}$, should present low critical cooling rates and are thus good glass formers.

Only a few researchers have tested the CB method. For instance, Wichard and Day [6] determined the critical cooling rates for five compositions of the $\mathrm{Ga}_{2} \mathrm{O}_{3}-\mathrm{CaO}$ system using the $\mathrm{CB}$ method and also an alternative technique. This second method is here denominated WD, and consists of repeatedly heating up a thin layer of glass around a $\mathrm{Pt}-$ $10 \% \mathrm{Rh}$ thermocouple bead, cooling it down at different rates and then recording eventual exothermic crystallization peak temperatures on cooling in a temperature versus time graph. The crystallization peak is absent when the cooling rate is faster than $q_{\mathrm{cr}}$. The critical cooling rate is then obtained from a $\Delta T_{\mathrm{c}}^{\mathrm{c}}$ versus $\log q$ plot for $\Delta T_{\mathrm{c}}^{\mathrm{c}}$ tending to infinity. Wichard and Day melted each composition between 150 and $250^{\circ} \mathrm{C}$ above its respective liquidus and cooled them at least 30 times at various rates to record exothermic crystallization peaks. The $q_{\mathrm{cr}}$ determined by the CB method (using a Pt crucible) and the experimental values agreed.

The WD method was afterwards used to determine critical cooling rates for $\mathrm{CaO}-\mathrm{Ga}_{2} \mathrm{O}_{3}-\mathrm{SiO}_{2}[7]$ and $\mathrm{BaO}-\mathrm{TiO}_{2}-$ $\mathrm{SiO}_{2}$ [8] glasses confirming the expected tendency of increasing GFA with increasing silica content.

Huang et al. [4] compared the $\mathrm{CB}$ and WD methods by studying the nucleating power of $\mathrm{Pt}, \mathrm{Au}, \mathrm{P}_{2} \mathrm{O}_{5}$ and $\mathrm{TiO}_{2}$ in a $40 \mathrm{Li}_{2} \mathrm{O} \cdot 60 \mathrm{SiO}_{2}$ glass. They showed that $q_{\mathrm{cr}}$ increases with the amount of $\mathrm{Pt}$ and $\mathrm{Au}$ added, but the effect of $\mathrm{Pt}$ is stronger than that of $\mathrm{Au}$; while $\mathrm{TiO}_{2}$ practically does not change the $q_{\mathrm{cr}}$, and $\mathrm{P}_{2} \mathrm{O}_{5}$ decreases it. As regards to the WD method, the sample that yielded a smooth cooling curve (without any exothermic crystallization peak detected by a thermocouple) was checked by optical microscopy and the respective cooling rate was used to estimate $q_{\text {cr }}$ when no crystals were detected. If some crystals were observed, the sample was melted again and cooled at a 
slightly higher rate until it was free of crystals. The two methods were in excellent agreement.

Later on, Cabral et al. [9] noticed that $\Delta T_{\mathrm{c}}^{\mathrm{c}}$ in Eq. (2) can only vary between zero and $T_{\mathrm{m}}$, such that in practice $\Delta T_{\mathrm{c}}^{\mathrm{c}}$ is limited by $\left(T_{\mathrm{m}}-T_{\mathrm{g}}\right)$ and thus never tends to infinity. Those authors then proposed a more realistic expression for $q_{\mathrm{cr}}$ based on the $\mathrm{CB}$ derivation, denominated $\mathrm{CB}^{*}$, given by the following equation:

$\ln q_{\mathrm{cr}}=A^{*}-\frac{B^{*}}{T_{\mathrm{m}}^{2}}$,

where $A^{*}$ and $B^{*}$ are constants. Nevertheless, results from the $\mathrm{CB}$ and $\mathrm{CB}^{*}$ equations were not significantly different. Their research indicated that the glass stability parameter proposed by Hrubÿ $\left(K_{\mathrm{H}}\right)$ - to be described later - is related to the $q_{\mathrm{cr}}$.

Recently, Ray et al. [10] proposed a new DTA method to measure $q_{\mathrm{cr}}$, which takes the crystallization peak height or area on the heating path, instead of the cooling path. Prior to heating experiments at a fixed rate, the samples are heated above the melting point and subsequently cooled at different rates, resulting in different crystalline fractions. The subsequent crystallization peak heights or areas in DTA traces are proportional to the amount of crystalline and residual glass present, such that increasing the cooling rate in the previous treatment increases the fraction of glass that can latter transform in the heating path. $q_{\mathrm{cr}}$ is the rate of the prior cooling experiment that first yields the maximum crystallization peak height or area in the following heating, indicating that glass always results for subsequent increasing of the cooling rate. This method was suggested to be also suitable for liquids that show small or undetectable crystallization peak on cooling due to too small crystallization heat or crystallization rate. The technique was tested for a $38 \mathrm{Na}_{2} \mathrm{O} \cdot 62 \mathrm{SiO}_{2}$ glass with a known $q_{\text {cr }}$ giving an excellent agreement.

Several other authors have formulated a number of GFA criteria and calculated $q_{\mathrm{cr}}$ using melt or crystallization parameters (see Refs. [1,11] and cited references therein).

\subsubsection{Our method and expression for $q_{c r}$}

Here we use the kinetic theory of Johnson-Mehl [12], Avrami [13-15] and Kolmogorov [16] (the JMAK theory) to derive and calculate the critical cooling rate needed to avoid a certain cumulative surface crystallized fraction, $X_{\mathrm{c}}$, on the cooling path. For small surface fraction crystallized $(X<0.1)$ in an isothermal process, $X \sim g \cdot N_{\mathrm{s}} \cdot u(T)^{2} \cdot t^{2}$. For a non-isothermal process with a constant cooling rate $q=\mathrm{d} T / \mathrm{d} t$ from the melting point to $T_{\mathrm{g}}$, one can easily demonstrate that the critical cooling rate $q_{\mathrm{cr}}$ is given by

$q_{\mathrm{cr}}=\sqrt{\frac{g N_{\mathrm{s}}}{X_{\mathrm{c}}}}\left|\int_{T_{\mathrm{m}}}^{T_{\mathrm{g}}} u(T) \mathrm{d} T\right|$

where $g$ is the crystal shape factor - which is 4 for square crystals, $2 \pi$ for ellipsoidal crystals and $\pi$ for circular crystals (on a glass surface). The vertical line in Eq. (5) indicates the absolute value of the integral of the crystal growth rate $u(T)$. Differently of previous research [111,17-19], which employed theoretically calculated growth rates, in this paper we use smooth experimental crystal growth rate curves $u(T)$ by fitting theoretical equations to experimental data in the range $T_{\mathrm{m}}$ to $\sim T_{\mathrm{g}}$, for each one of the eight glasses studied - please look at Ref. [20] for details. The detectable degree of surface crystallization, $X_{\mathrm{c}}$, is considered to be $0.1 \%$. We assume the most common nucleation mechanism, i.e., heterogeneous surface nucleation from a fixed number of sites, where $N_{\mathrm{s}}$ is the constant number density of crystals per unit area - which we consider to be $10^{4}$ crystals $/ \mathrm{m}^{2}$ (a typical value for fractured surfaces see Müller [21]).

\subsubsection{Glass stability parameters}

There are several parameters regarding glass stability on heating. For instance, Turnbull [22] proposed a now classical parameter based on the assumption that the nucleation frequency in an undercooled melt is inversely proportional to its viscosity, $\eta$. The ratio

$K_{\mathrm{T}}=\frac{T_{\mathrm{g}}}{T_{\mathrm{m}}}$

is the reduced glass transition temperature, and $T_{\mathrm{m}}$ is the melting point (or the liquidus, $T_{1}$, instead of $T_{\mathrm{m}}$, when applicable). Turnbull adopted the classical nucleation theory and used $K_{\mathrm{T}}$ as a criterion for glass formation as the avoidance of a single nucleation event. Earlier on, Kauzmann had also mentioned the significance of this same ratio [23].

To the best of our knowledge, Weinberg [24] was one of the first to use another parameter, whose 'father' is unknown. Therefore, we will name it the Weinberg parameter:

$K_{\mathrm{W}}=\frac{T_{x}^{\mathrm{h}}-T_{\mathrm{g}}}{T_{\mathrm{m}}}$.

Actually Weinberg used the peak maximum $T_{\mathrm{c}}^{\mathrm{h}}$ and not the onset $T_{x}^{\mathrm{h}}$. In this paper $T_{\mathrm{c}}^{\mathrm{h}}$ and $T_{x}^{\mathrm{h}}$ are interchanged and both are tested, as we will describe bellow.

Hrubÿ proposed his own parameter to probe glass stability against crystallization on heating [18], $K_{\mathrm{H}}$, as defined by

$K_{\mathrm{H}}=\frac{T_{x}^{\mathrm{h}}-T_{\mathrm{g}}}{T_{\mathrm{m}}-T_{x}^{\mathrm{h}}}$

According to Hrubÿ, the higher is the value of $K_{\mathrm{H}}$ for a certain glass, the higher its stability against crystallization on heating and, presumably, the higher the glass ability to vitrify on cooling.

Recently, Lu and Liu $[25,26]$ proposed a new criterion, $K_{\mathrm{LL}}$,

$K_{\mathrm{LL}}=\frac{T_{x}^{\mathrm{h}}}{T_{\mathrm{g}}+T_{\mathrm{m}}}$,

which was analyzed for 49 metallic glasses, 23 oxide glasses and 25 cryoprotective aqueous solutions, showing 
reasonable, but not excellent, correlations with the respective critical cooling rates obtained by different methods and several authors.

The following GS parameter was proposed by Saad and Poulain [27].

$K_{\mathrm{SP}}=\left(T_{x}^{\mathrm{h}}-T_{\mathrm{g}}\right)\left(T_{\mathrm{c}}^{\mathrm{h}}-T_{x}^{\mathrm{h}}\right) / T_{\mathrm{g}}$.

As far as we know, there are at least other four additional parameters for GS that also rely on the characteristic DSC temperatures $T_{\mathrm{g}}, T_{\mathrm{m}}, T_{\mathrm{c}}^{\mathrm{h}}$ and $T_{x}^{\mathrm{h}}$. The origin of $K_{1}$ (Eq. (10)) is unknown to us. Hrubÿ [18] proposed $K_{2}$ (Eq. (11)) in 1972. Tran et al. [28] applied this criterion to fluorozirconate glasses in 1982. Angell [29] was probably the first to suggest that $K_{2}$ is a good indicator of GS. Drexhage et al. [30], Almeida and Mackenzie [31], and Cooper and Angell [32] also reached similar conclusions. $K_{3}$ (Eq. (12)) was proposed by Wakasugi et al. [33], while $K_{4}$ (Eq. (13)) was probably proposed by Weinberg [24]. It is not always possible to precisely track back the birth of all these parameters, therefore, for simplicity, we will denominate them simply as:

$K_{1}=T_{\mathrm{m}}-T_{\mathrm{g}}$,

$K_{2}=T_{x}^{\mathrm{h}}-T_{\mathrm{g}}$,

$K_{3}=T_{x}^{\mathrm{h}} / T_{\mathrm{m}}$,

$K_{4}=\left(T_{x}^{\mathrm{h}}-T_{\mathrm{g}}\right)\left(T_{\mathrm{c}}^{\mathrm{h}}-T_{x}^{\mathrm{h}}\right) / T_{\mathrm{m}}$.

In this paper we alternatively substitute $T_{x}^{\mathrm{h}}$ by $T_{\mathrm{c}}^{\mathrm{h}}$ when applicable (except for Saad and Poulain's parameter, and $K_{4}$, Eqs. (9) and (13)) and calculate the GS parameters given by the above expressions. With the interchangeable $T_{x}^{\mathrm{h}}$ and $T_{\mathrm{c}}^{\mathrm{h}}$ our analysis thus involved not nine, but fourteen stability parameters.

There are other more complex GS parameters, such as that of Duan et al. [34], which relates kinetics and thermodynamics in the form $K_{\mathrm{D}}(T)=v \exp (-E D / R T)$, where $R$ is the universal gas constant, $D=T_{x}^{\mathrm{h}}\left(T_{\mathrm{c}}^{\mathrm{h}}-T_{x}^{\mathrm{h}}\right) /\left[T_{\mathrm{m}}\left(T_{\mathrm{m}}-\right.\right.$ $\left.\left.T_{\mathrm{g}}\right)\right], v$ is a frequency factor and $E$ is an activation energy for crystallization. But $D, v$ and $E$ are derived from DSC or DTA curves obtained at different heating rates, which were not performed in this work.

Ota et al. [19] related the viscosity at the melting point, $\eta\left(T_{\mathrm{m}}\right)$, with critical cooling rates. It is thus possible to consider $\eta\left(T_{\mathrm{m}}\right)$ as a GS parameter, as proposed by Tamman many years ago. Nevertheless, in this work we only test GS parameters that are possible to obtain from simple DSC or DTA experiments.

\subsubsection{GFA versus $G S$}

Using theoretical expressions for crystal nucleation and growth rates, and the JMAK theory, considering homogeneous nucleation and screw dislocation growth in stoichiometric glasses, Weinberg [35] concluded that GFA and GS, defined by $\left(T_{\mathrm{c}}^{\mathrm{h}}-T_{\mathrm{g}}\right) / T_{\mathrm{m}}$, are ill related concepts. Weinberg compared the trends in GFA and GS with systematic changes in the melting entropy,
$\Delta S_{\mathrm{m}}$, and the viscosity parameters in the Vogel-Fulcher-Tamman (VFT) expression in terms of the reduced temperature $T_{\mathrm{r}}=T / T_{\mathrm{m}}: \eta=\eta_{0} \exp \left[b /\left(T_{\mathrm{r}}-T_{\text {or }}\right)\right]$, i.e. the reduced Kauzmann temperature, $T_{\text {or }}$, the pre-exponential, $\eta_{0}$, and the constant $b$. The parameter $b$ was assumed to vary concomitantly with $\eta_{0}$. $\mathrm{He}$ also correctly pointed out that for heterogeneous crystallization, the critical cooling rate and GS depend upon sample size, shape and surface condition, and then the concept of gauging GFA by GS is difficult to find practical interest.

In a subsequent work, Weinberg [24] used the JMAK theory to derive the time necessary to crystallize a minimum detectable fraction, considering again classical homogeneous nucleation and screw dislocation growth in stoichiometric glasses. He then used the time criteria to assess GFA and test the reliability of two particular GS parameters, given by the expressions: $\left(T_{x}^{\mathrm{h}}-T_{\mathrm{g}}\right) /$ $T_{\mathrm{m}}$ and $\left(T_{x}^{\mathrm{h}}-T_{\mathrm{g}}\right)\left(T_{\mathrm{c}}^{\mathrm{h}}-T_{x}^{\mathrm{h}}\right) / T_{\mathrm{m}}$. Weinberg calculated these GS parameters by using nucleation and growth equations and the JMAK equation, and varied them by changing the physical parameters that control the crystallization rate. He observed that the stability of glasses having parallel viscosity curves $\eta(T)$ could be qualitatively evaluated by the two expressions above described, but they are not quantitatively reliable and none of them appears to be best. However, he concluded that for glasses for which $\eta(T)$ significantly differed in the region of $T_{\mathrm{g}}$, these stability criteria can be misleading.

Cabral et al. [17] used the nose method (explained above) in a $T T T$ curve built from experimental $I(T)$ and $u(T)$ to calculate $q_{\text {cr }}$ for four stoichiometric glasses that exhibit homogeneous nucleation: $\mathrm{Li}_{2} \mathrm{O} \cdot 2 \mathrm{SiO}_{2}, \quad \mathrm{Na}_{2} \mathrm{O}$. $2 \mathrm{CaO} \cdot 3 \mathrm{SiO}_{2}, \mathrm{BaO} \cdot 2 \mathrm{SiO}_{2}$ and $2 \mathrm{Na}_{2} \mathrm{O} \cdot \mathrm{CaO} \cdot 3 \mathrm{SiO}_{2}$. They compared $q_{\text {cr }}$ with the stability parameter of Hrubÿ [18], Eq. (7), and concluded that these $q_{\mathrm{cr}}$ and $K_{\mathrm{H}}$ were related. They also showed that the alternative use of $T_{\mathrm{c}}^{\mathrm{h}}$ instead of $T_{x}^{\mathrm{h}}$ in the $K_{\mathrm{H}}$ expression did not result in significant differences.

Later on Cabral et al. [9] extended and improved their approach by including three other glasses $-\mathrm{Li}_{2} \mathrm{O}$. $2 \mathrm{SiO}_{2} \cdot \mathrm{OH}, 2 \mathrm{BaO} \cdot \mathrm{TiO}_{2} \cdot 2 \mathrm{SiO}_{2}$ and $44 \mathrm{Na}_{2} \mathrm{O} \cdot 56 \mathrm{SiO}_{2}-$ in addition to those four used in Ref. [17], and studied again the correlation between $q_{\mathrm{cr}}$ and $K_{\mathrm{H}}$. However, they used a DSC method of cooling liquids at different rates (the $\mathrm{CB}^{*}$ method - described above) as a measure of critical cooling rate rather than calculating $q_{\mathrm{cr}}$ by the nose method. In addition, they detected a strong effect of the DSC sample holder pan on the crystallization peak position on cooling the melt. Platinum and alumina pans had strongly catalyzed nucleation, but graphite pans proved to be suitable for obtaining the crystallization parameters free from these effects. Despite this fact, they used their extensive DSC results obtained using a Pt pan to calculate the $q_{\text {cr }}$ and Hrubÿ's GS. But, to minimize the nucleation effect of $\mathrm{Pt}$, they repeated several times the cooling procedure in the DSC and chose the crystallization peak at the 
lowest temperature among the several runs (that probably undergoes the least interference of the pan material). Due to these problems, only the $\mathrm{Li}_{2} \mathrm{O} \cdot 2 \mathrm{SiO}_{2}$ glass presented $q_{\mathrm{cr}}$ of comparable magnitude to that estimated by the nose method. All the other glasses presented $\mathrm{CB}^{*}$ values twice to six times higher than the $q_{\text {cr }}$ calculated by the nose method. Nevertheless, these authors found a general trend correlating the $q_{\mathrm{cr}}$ and Hrubÿ's parameter, reinforcing their idea that GFA can be estimated by Hrubÿ's GS parameter.

Concomitantly to the study of Cabral et al. [9], Avramov et al. [2] theoretically investigated the possible relationship between GFA and GS for both homogeneous and heterogeneous nucleation, in a similar way to that of Weinberg [35], but assuming that the activation energy for viscous flow, $b$, varies independently of the pre-exponential term, $\eta_{0}$, in the viscosity expression. They demonstrated that if this assumption about $b$ and $\eta_{0}$ is valid, GS and GFA are indeed related concepts.

Differently of previous works, we now test glasses having predominant heterogeneous (surface) nucleation and use powdered specimens to privilege this type of nucleation. We then use the JMAK expression for surface nucleation, one estimated value of the number of nucleation sites per unit area and experimental growth rates for each glass, which vary by four orders of magnitude for the eight systems analyzed, to calculate the critical cooling rates. We then compare the calculated $q_{\mathrm{cr}}$ for each glass with fourteen different (measured) GS parameters.

\section{Experimental and calculational procedures}

We carried out DSC experiments using powdered samples of eight glasses: $\mathrm{GeO}_{2}(\mathrm{G}), \mathrm{PbO} \cdot \mathrm{SiO}_{2}$ (PS), $\mathrm{Na}_{2} \mathrm{O} \cdot 2 \mathrm{SiO}_{2} \quad\left(\mathrm{NS}_{2}\right), \quad 2 \mathrm{MgO} \cdot 2 \mathrm{Al}_{2} \mathrm{O}_{3} \cdot 5 \mathrm{SiO}_{2}$ (Cordierite, $\left.\mathrm{M}_{2} \mathrm{~A}_{2} \mathrm{~S}_{5}\right), \mathrm{Li}_{2} \mathrm{O} \cdot 2 \mathrm{SiO}_{2}\left(\mathrm{LS}_{2}\right), \mathrm{CaO} \cdot \mathrm{MgO} \cdot 2 \mathrm{SiO}_{2}$ (Diopside, $\mathrm{CMS}_{2}$ ), $\mathrm{CaO} \cdot \mathrm{Al}_{2} \mathrm{O}_{3} \cdot 2 \mathrm{SiO}_{2}$ (Anorthite, $\mathrm{CAS}_{2}$ ) and $\mathrm{Li}_{2} \mathrm{O}$ $2 \mathrm{~B}_{2} \mathrm{O}_{3}\left(\mathrm{LB}_{2}\right)$. Glassy $\mathrm{GeO}_{2}$ was prepared in the Otto Schott Institute in Jena (Germany) by A.C.M. Rodrigues and R. Keding; the $\mathrm{M}_{2} \mathrm{~A}_{2} \mathrm{~S}_{5}$ was prepared by R. Müller at BAM, Berlin (Germany); the anorthite and $\mathrm{NS}_{2}$ glasses were produced by E.D. Zanotto at Sheffield University (UK); the other five glasses were produced by the present authors in the Vitreous Materials Laboratory at UFSCar (Brazil). These stoichiometric glasses were melted above the melting points of the respective isochemical crystals in Pt crucibles for a few hours, homogenized and quenched. The processing conditions are shown in Table 1.

All the glasses were chemically analyzed and the results are shown in Table 2. In general, their compositions closely agree with the respective stoichiometric formulas. All these glasses were crushed by hand in an agate mortar and pistil, and the resulting powder was sieved to form two samples with different particle sizes, 22-38 $\mu \mathrm{m}$ (fine powder) and $150-177 \mu \mathrm{m}$ (coarser powder). DSC scans were obtained for all glasses using the fine and coarse samples to evaluate the effect of heterogeneous crystallization on the DSC crystallization peaks and, consequently, in the GS parameters. About $20-40 \mathrm{mg}$ of each sample were analyzed in a Netzsch 404 DSC using a Pt crucible. The heating rate was

Table 1

Melting temperatures, times and quenching techniques used to produce glasses

\begin{tabular}{llll}
\hline Glasses & Temperature $\left({ }^{\circ} \mathrm{C}\right)$ & Time & Quench by \\
\hline $\mathrm{G}_{\text {(OSI-Jena) }}$ & 1500 & $2 \mathrm{~h}$ & Casting on a steel plate \\
PS $_{(\text {UFSCar) }}$ & 1250 & $2 \mathrm{~h}$ & Pressing $^{\mathrm{a}}$ \\
$\mathrm{NS}_{2 \text { (Sheffield) }}$ & 1300 & $5 \mathrm{~h} /$ stirred during $3 \mathrm{~h}$ & Casting on a steel plate \\
$\mathrm{M}_{2} \mathrm{~A}_{2} \mathrm{~S}_{5(\text { BAM })}$ & 1590 & $8 \mathrm{~h}$ & Casting on a steel plate \\
LS $_{2 \text { (UFSCar) }}$ & 1350 & $2.5 \mathrm{~h} /$ remelted for $30 \mathrm{~min}$ & Casting on a graphite mold \\
$\mathrm{CMS}_{2 \text { (UFSCar) }}$ & 1500 & $2 \mathrm{~h} /$ remelted 3 times for $30 \mathrm{~min}$ & Casting on a steel plate \\
$\mathrm{CAS}_{2 \text { (Sheffield) }}$ & 1600 & $5 \mathrm{~h}$ & Pressing \\
LB $_{2 \text { (UFSCar) }}$ & 1000 & $2 \mathrm{~h}$ & Pressing $^{\mathrm{a}}$ \\
\hline
\end{tabular}

${ }^{\text {a }}$ The liquid was poured and pressed between two steel plates.

Table 2

Chemical analyses of the present glasses ( $\mathrm{wt} \%)$

\begin{tabular}{|c|c|c|c|c|c|c|c|c|c|}
\hline Glasses & $\mathrm{SiO}_{2}$ & $\mathrm{CaO}$ & $\mathrm{MgO}$ & $\mathrm{PbO}$ & $\mathrm{Na}_{2} \mathrm{O}$ & $\mathrm{Li}_{2} \mathrm{O}$ & $\mathrm{Al}_{2} \mathrm{O}_{3}$ & $\mathrm{~B}_{2} \mathrm{O}_{3}$ & $\mathrm{GeO}_{2}$ \\
\hline G & - & - & - & - & - & - & - & - & 100 \\
\hline PS & 22.64 & - & - & 77.03 & - & - & - & - & - \\
\hline $\mathrm{NS}_{2}$ & 66.08 & - & - & - & 33.53 & - & - & - & - \\
\hline $\mathrm{LS}_{2}$ & 80.31 & - & - & - & - & 19.69 & - & - & - \\
\hline $\mathrm{CMS}_{2}$ & 56.64 & 26.40 & 16.94 & - & - & - & - & - & - \\
\hline $\mathrm{CAS}_{2}$ & 43.42 & 20.19 & - & - & - & - & 36.39 & - & - \\
\hline
\end{tabular}




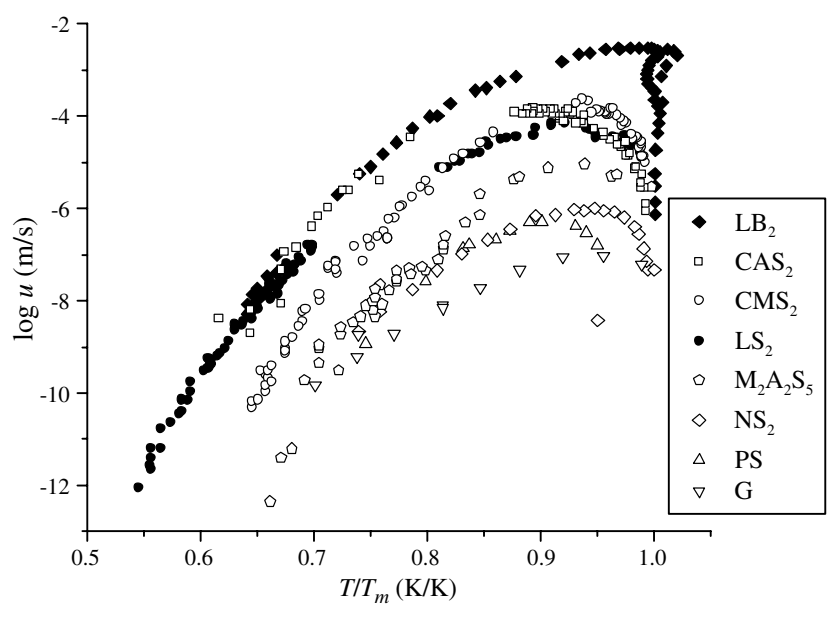

Fig. 1. Experimental crystal growth rates in eight glasses, corrected by the Herron and Bergeron equation [37] for the interface temperature. For details see Ref. [20]. Full symbols refer to glasses that also show internal homogeneous nucleation; open symbols refer to glasses that only show surface heterogeneous nucleation in laboratory time scales.

kept at $10 \mathrm{~K} / \mathrm{min}$. In the cases when more than one crystallization peak appeared in the DSC curve, the onset and peak temperatures $\left(T_{x}^{\mathrm{h}}\right.$ and $T_{\mathrm{c}}^{\mathrm{h}}$, respectively) of the first (at the lowest temperature) peak were taken to calculate the GS of the glass. With the experimental values of $T_{\mathrm{g}}$, $T_{x}^{\mathrm{h}}, T_{\mathrm{c}}^{\mathrm{h}}$ and $T_{\mathrm{m}}$, it was then possible to determine the glass stability parameters from Eqs. (5)-(13) and, when applicable, their equivalent by changing $T_{x}^{\mathrm{h}}$ by $T_{\mathrm{c}}^{\mathrm{h}}$.

To correctly calculate the critical cooling rates, the crystal morphologies were determined by optical microscopy in samples heat treated at $T_{\mathrm{g}}<T<1.2 T_{\mathrm{g}}$ chosen according to the known $u(T)$ curves (see Fig. 1) to grow crystals of about $50 \mu \mathrm{m}$ in $30 \mathrm{~min}$, i.e. before they heavily impinge and cover the whole surface.

According to the extensive study of Müller et al. [36], the number density of surface nucleation sites $\left(N_{\mathrm{s}}\right)$ on several glasses having different surface finish, e.g. mechanically polished, fractured, fire-polished, etc., and crystallized under different environments of thermal treatments varies from $10^{4}$ to $10^{11}$ crystals $/ \mathrm{m}^{2}$, although fire polished and other types of pristine surfaces may sometimes have almost no nucleation sites. To calculate the $q_{\mathrm{cr}}$ by Eq. (4) to allow a comparison among all glasses, we considered $N_{\mathrm{s}}$ constant and equal to $10^{4}$ crystals $/ \mathrm{m}^{2}$, which corresponds to the smallest value reported for fractured surfaces. The choice of this small $N_{\mathrm{s}}$ was made having in mind $q_{\mathrm{cr}}$ as derived from the glass forming ability concept by limiting crystallization when cooling a melt. This assumption about $N_{\mathrm{s}}$ and its implications for the results of this research will be discussed later.

The $u(T)$ curves used here were obtained from the literature and are resumed in Ref. [20]. Crystallization is an exothermic process and the knowledge of the crystal/liquid interface temperature is essential for analyzing crystal growth kinetics. Based on direct measurements for several glasses, Herron and Bergeron [37] successfully obtained an empirical equation to estimate the liquid-crystal interface temperature for growing crystals. We thus corrected $u(T)$ for the interface temperatures for all systems studied here (see details in Ref. [20]), but calculations with and without these corrections demonstrated that the main conclusions about the critical cooling rates would not change.

The maximum allowed crystalline fraction, $X_{\mathrm{c}}$, may be established depending on one's ability to detect small quantities of crystals in a glass matrix. The maximum crystalline fraction $X_{\mathrm{c}}$ allowed to consider a material as a glass is usually considered to be between $10^{-2}$ and $10^{-6}$. Here we use a surface fraction crystallized $X_{\mathrm{c}}=0.1 \%$, i.e. a minimum surface crystallized fraction detectable by $\mathrm{X}$-ray diffraction experiments.

For each glass we calculate GS using DSC data obtained for fine and coarse powders. As $q_{\mathrm{cr}}$ range covers a much wider interval than the GS parameters, we take the logarithmic scale to plot $q_{\mathrm{cr}}$ versus GS (in linear scale) for all fourteen GS parameters.

\section{Results}

Fig. 1 shows literature data for experimental crystal growth rates as a function of temperature, corrected by the Herron and Bergeron equation [37]. These data are plotted against the reduced temperature $T / T_{\mathrm{m}}$ to allow a comparison of all glasses. The highest maximum growth rate is that of $\mathrm{LB}_{2}\left(3 \times 10^{-3} \mathrm{~m} / \mathrm{s}\right)$ and the slowest refers to $\mathrm{GeO}_{2}\left(9 \times 10^{-8} \mathrm{~m} / \mathrm{s}\right)$. These crystal growth rate peaks are at about $0.95 T_{\mathrm{m}}$ and vary by 10 orders of magnitude, from $T_{\mathrm{g}}$ to $T_{\mathrm{m}}$ !

The observed crystal morphologies and respective shape factors, $g$, are shown in Table 3. To simplify our calculations, for hexagonal shaped crystals, such as anorthite and $\mu$-cordierite, the morphologies were considered ellipsoidal. For lead metasilicate, the crystal morphology was needle-like, growing in spherulitic habit, and thus was considered spherical. It should be noted that crystal morphology can vary with temperature. However, according to Eq. (4) $q$ is not strongly dependent of the shape factor. The critical cooling rates were alternatively calculated with Eq. (4) considering crystals having only spherical morphologies for all systems, i.e. using $g=\pi$, to evaluate the effect of $g$, but the results (not shown) did not change much as compared with the real morphologies presented on Table 3. For example, if one chooses circular or squared crystals for diopside, the order of magnitude of $q_{\mathrm{cr}}$ remains the same and the main conclusions of this work do not change.

The integral in Eq. (4) was obtained numerically by the area under the $u(T)$ curve fitted to the data in Fig. 1. Two methods of numerical integration were used: one by integrating data directly from Fig. 1, and other by integrating a smooth curve that resulted from a crystal growth model (normal, screw dislocation or 2D surface nucleation growth, when applicable) fitted to the same data set. These two procedures gave similar results, shown in Table 4. 
Table 3

Mechanism of growth, crystal morphologies obtained near $T_{\mathrm{g}}$ of each glass, shape factors, $g$, and critical cooling rates $q_{\mathrm{cr}}$ for different glasses

\begin{tabular}{lllll}
\hline Glasses & Mechanism & Crystal morphology near $T_{\mathrm{g}}$ & $g$ factor & $q_{\mathrm{cr}}(\mathrm{K} / \mathrm{s})$ \\
\hline $\mathrm{G}$ & $\mathrm{N}$ & $\square$ & 4 & 0.073 \\
$\mathrm{PS}$ & $2 \mathrm{D}$ & $*$ & $\pi$ & 0.28 \\
$\mathrm{NS}_{2}$ & $\mathrm{SD}$ & 0 & $2 \pi$ & 2.43 \\
$\mathrm{M}_{2} \mathrm{~A}_{2} \mathrm{~S}_{5}$ & $*$ & - & $2 \pi$ & 11.3 \\
$\mathrm{LS}_{2}$ & $*$ & 0 & $2 \pi$ & 70.6 \\
$\mathrm{CMS}_{2}$ & $\mathrm{SD}$ & $\square$ & 4 & 169 \\
$\mathrm{CAS}_{2}$ & 2D & - & $2 \pi$ & 236 \\
$\mathrm{LB}_{2}$ & $*$ & $\square$ & 2 & $1.52 \times 10^{3}$ \\
\hline
\end{tabular}

Morphologies: $\square$ : squared; $\square$ : rectangular; 0: ellipsoidal; : hexagonal; and $*$ : spherulitic needle-like. The crystal growth models are indicated as: normal $(\mathrm{N})$, screw dislocation (SD) and surface nucleated (2D). The systems indicated with $\left(^{*}\right)$ present two possible crystal growth mechanisms: SD or 2D. $q_{\mathrm{cr}}$ from $\mathrm{G}$ and $\mathrm{NS}_{2}$ glasses were calculated using $u_{\max }\left(T_{\mathrm{m}}-T_{\mathrm{g}}\right)$. Details on crystal growth rate data are given in Ref. [20].

Table 4

Integration of $\int_{T_{\mathrm{g}}}^{T_{\mathrm{m}}} u(T) \mathrm{d} T$ by different methods, maximum crystal growth rates, temperature at $u_{\max }$ and temperature range observed for crystallization

\begin{tabular}{|c|c|c|c|c|c|c|c|}
\hline \multirow[t]{2}{*}{ Glasses } & \multirow[t]{2}{*}{$u_{\max }(\mathrm{m} / \mathrm{s})$} & \multirow[t]{2}{*}{$T_{\max }(\mathrm{K})$} & \multirow[t]{2}{*}{$\Delta T$ range } & \multicolumn{4}{|l|}{$\int_{T_{\mathrm{g}}}^{T_{\mathrm{m}}} u(T) \mathrm{d} T(\mathrm{~m} \mathrm{~K} / \mathrm{s})$} \\
\hline & & & & Integration with data & Integration with model & $u_{\max } T_{\max } / 10$ & $u_{\max }\left(T_{\mathrm{m}}-T_{\mathrm{g}}\right) / 5$ \\
\hline$\overline{\mathrm{G}}$ & $9.33 \times 10^{-8}$ & 1326 & $1.26 T_{\mathrm{g}}-T_{\mathrm{m}}$ & $1.469 \times 10^{-5}$ & $1.402 \times 10^{-5}$ & $1.24 \times 10^{-5}$ & $1.155 \times 10^{-5}$ \\
\hline $\mathrm{NS}_{2}$ & $3.67 \times 10^{-6}$ & 1155 & $1.16 T_{\mathrm{g}}-T_{\mathrm{m}}$ & $1.088 \times 10^{-4}$ & $1.176 \times 10^{-4}$ & $4.00 \times 10^{-4}$ & $3.06 \times 10^{-4}$ \\
\hline $\mathrm{M}_{2} \mathrm{~A}_{2} \mathrm{~S}_{5}$ & $9 \times 10^{-6}$ & 1523 & $0.99 T_{\mathrm{g}}-T_{\mathrm{m}}$ & 0.00143 & 0.00121 & 0.00140 & 0.00101 \\
\hline $\mathrm{LS}_{2}$ & $6.87 \times 10^{-5}$ & 1188 & $0.98 T_{\mathrm{g}}-T_{\mathrm{m}}$ & 0.00891 & 0.00904 & 0.00820 & 0.00796 \\
\hline $\mathrm{LB}_{2}$ & $2.95 \times 10^{-3}$ & 993 & $1.04 T_{\mathrm{g}}-T_{\mathrm{m}}$ & 0.3407 & 0.319 & 0.293 & 0.252 \\
\hline
\end{tabular}

Table 5

Characteristic temperatures obtained from DSC traces recorded at $10 \mathrm{~K} / \mathrm{min}$ for fine and coarse glass powders

\begin{tabular}{|c|c|c|c|c|c|c|c|}
\hline \multirow[t]{2}{*}{ System } & \multirow[t]{2}{*}{$T_{\mathrm{m}}(\mathrm{K})$} & \multicolumn{3}{|l|}{ Fine } & \multicolumn{3}{|l|}{ Coarse } \\
\hline & & $T_{\mathrm{g}}(\mathrm{K})$ & $T_{x}^{\mathrm{h}}(\mathrm{K})$ & $T_{\mathrm{c}}^{\mathrm{h}}(\mathrm{K})$ & $T_{\mathrm{g}}(\mathrm{K})$ & $T_{x}^{\mathrm{h}}(\mathrm{K})$ & $T_{\mathrm{c}}^{\mathrm{h}}(\mathrm{K})$ \\
\hline G & 1388 & 819 & 1090 & 1174 & 821 & 1147 & 1187 \\
\hline $\mathrm{NS}_{2}$ & 1147 & 713 & 897 & 918 & 721 & 901 & 935 \\
\hline $\mathrm{M}_{2} \mathrm{~A}_{2} \mathrm{~S}_{5}$ & 1350 & 1072 & 1203 & 1238 & 1075 & 1227 & 1273 \\
\hline $\mathrm{LS}_{2}$ & 1306 & 740 & 819 & 886 & 742 & 821 & 924 \\
\hline $\mathrm{CMS}_{2}$ & 1664 & 988 & 1148 & 1187 & 989 & 1164 & 1209 \\
\hline
\end{tabular}

$T_{\mathrm{m}}$ is from the literature [20].

Taking the maximum $u(T)$ in Fig. 1, $u_{\max }$, the corresponding temperature $T_{\max }$ and the parameters $T_{\mathrm{g}}$ and $T_{\mathrm{m}}$ (given in Table 5), one may calculate some parameters such as $u_{\max } T_{\max } / 10$ and $u_{\max }\left(T_{\mathrm{m}}-T_{\mathrm{g}}\right) / 5$ for each glass in an attempt to get an easy approximation for the integral in Eq. (4). The results of these calculations are shown in Table 4 , compared with those resulting from numerical integrations. The importance of this procedure is explained on the basis that it was not simple to obtain crystal growth rates near $T_{\mathrm{g}}$ for all systems, such as $\mathrm{NS}_{2}$. The meaning of this finding will be discussed later in this article. The critical cooling rates, $q_{\mathrm{cr}}$, as calculated through Eq. (4), are shown in Table 3.
Typical DSC scans were obtained for all fine and coarse powders. Fig. 2 shows the DSC curves of the fine powders, which do not differ much from the coarse ones, then these last are not shown. The resulting characteristic temperatures and the melting temperatures obtained from the literature (see Ref. [20] for details) are shown in Table 5. For $\mathrm{M}_{2} \mathrm{~A}_{2} \mathrm{~S}_{5}$ the crystallizing phase was considered to be the metastable $\mu$-cordierite with an estimated melting temperature $T_{\mathrm{m}}^{\mu} \approx 1350{ }^{\circ} \mathrm{C}$ from the corresponding crystal growth rate curve [38]. The GS parameters were subsequently calculated considering the DSC characteristic temperatures for the coarse and fine powders, and the results are plotted in Figs. 3 and 4 as $q_{\text {cr }}$ versus GS in log-lin graphs. 

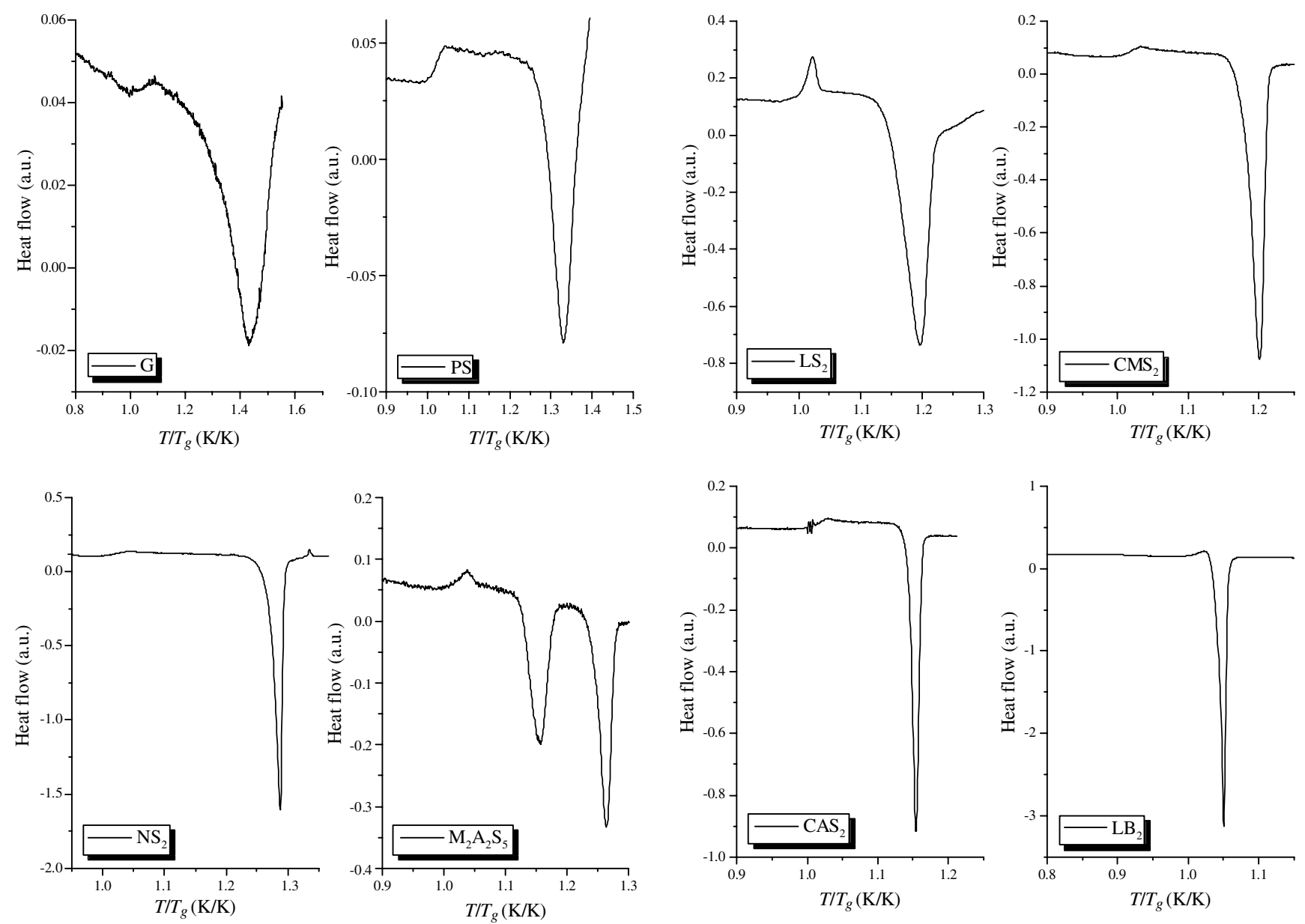

Fig. 2. DSC traces of G, PS, $\mathrm{NS}_{2}, \mathrm{M}_{2} \mathrm{~A}_{2} \mathrm{~S}_{5}, \mathrm{LS}_{2}, \mathrm{CMS}_{2}, \mathrm{CAS}_{2}$ and $\mathrm{LB}_{2}$ glasses using fine grained powders with a heating rate of $10 \mathrm{~K} / \mathrm{min}$.

\section{Discussion}

\subsection{On the data used and main assumptions for the calculations}

To simplify our analysis, the collection of crystal growth rates as a function of temperature from different authors for each particular system is represented by a unique symbol in Fig. 1. One can observe that these crystal growth rates show quite consistent trends and do not disperse much. We thus consider that the quality of the input $u(T)$ data is adequate.

The main assumption used in this paper refers to the number density of surface nuclei in Eq. (4), $N_{\mathrm{s}}$. It is quite difficult to precisely determine $N_{\mathrm{s}}$ for powders because the surface state and $N_{\mathrm{s}}$ are strongly dependent on the environment and on the way the powder is produced. To a first approximation, in the present calculations we suppose $N_{\mathrm{s}}=10^{4}$ cystals $/ \mathrm{m}^{2}$ and equal for all the oxide glasses used. However, this assumption has not been tested and is probably not good for general use, for instance for metallic or polymer glasses. It is reasonable to argue that oxide glasses prepared by equivalent procedures result in comparable surface states. But, to correctly calculate $q_{\mathrm{cr}}$ for any system one must devise a way to measure $N_{\mathrm{s}}$ and the effect of significant internal nucleation (when this is the case).

The parameters $N_{\mathrm{s}}$ and $X_{\mathrm{c}}$ here selected agree with values observed in common practice. Our conclusions are not altered if one chooses, for instance, $N_{\mathrm{s}}=10^{5}$ cystals/ $\mathrm{m}^{2}$ and $X_{\mathrm{c}}=1 \%$, which are also acceptable values, but using values that are too different from those considered here could lead to other conclusions.

From Table 4 one sees that there is very good agreement between numerical integration, using interpolated data from Fig. 1, and the model equations, using classical crystal growth mechanisms for $u(T)$. Details of fitting crystal growth expressions to experimental data can be found elsewhere [20]. The products $u_{\max } T_{\max } / 10$ and $u_{\max }\left(T_{\mathrm{m}}-T_{\mathrm{g}}\right) / 5$ are of the same order of magnitude as the more rigorous integrals, suggesting that to estimate GFA it is only necessary to know a few parameters, such as $u_{\max }, T_{\max }, T_{\mathrm{m}}$ and $T_{\mathrm{g}}$, and not the whole $u(T)$ between $T_{\mathrm{g}}$ and $T_{\mathrm{m}}$. This means that, for the case of heterogeneous surface nucleation considered here, the critical cooling rates are mostly affected by the maximum crystal growth rate, $u_{\max }$. Systems that present high $u_{\max }, T_{\max }$ or $\left(T_{\mathrm{m}}-T_{\mathrm{g}}\right)$ require high cooling rates to vitrify. Our proposal to estimate $q_{\mathrm{cr}}$ considering it proportional to $u_{\max }\left(T_{\mathrm{m}}-T_{\mathrm{g}}\right)$ can be obtained from Eq. (1) 

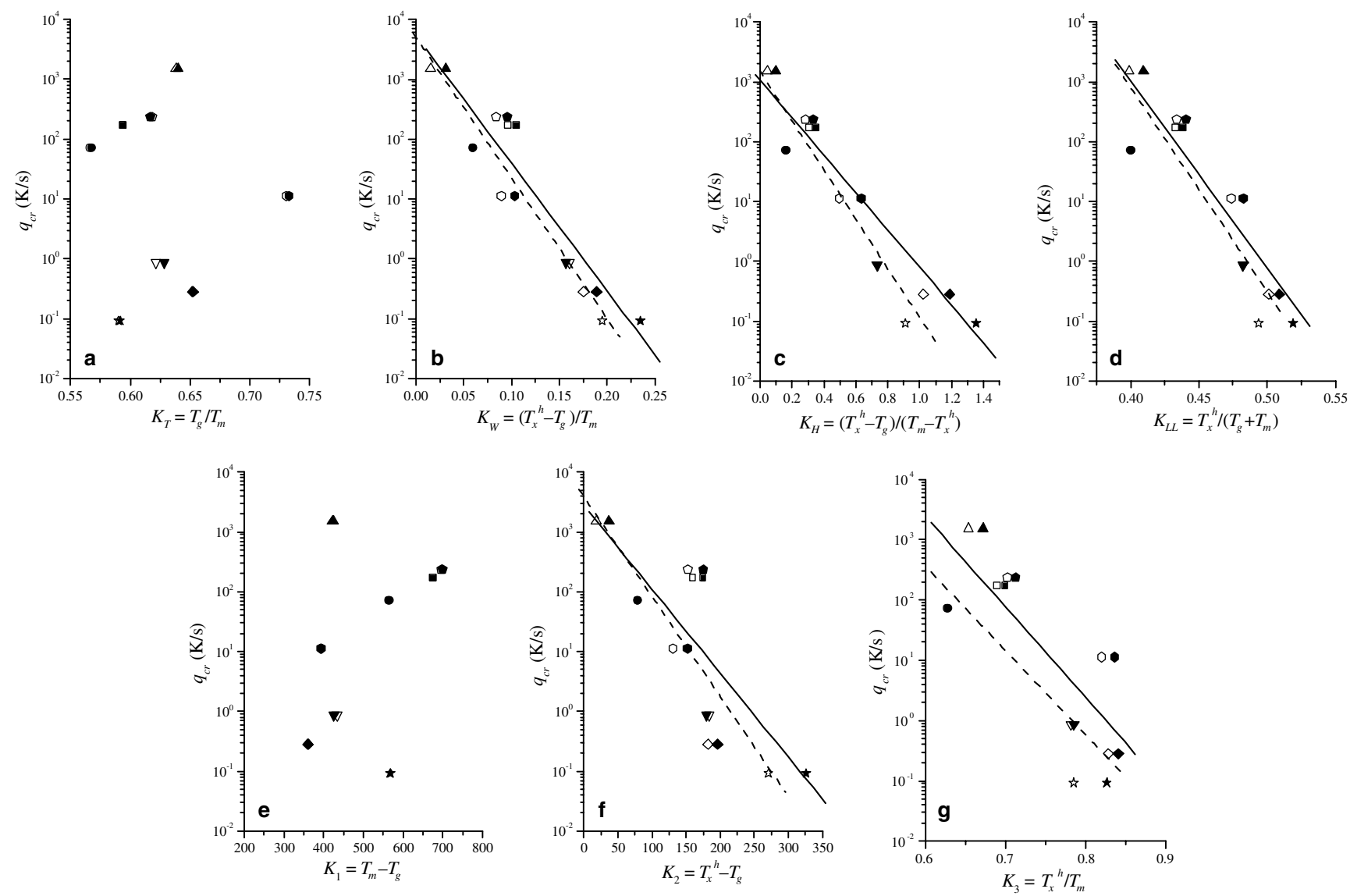

Fig. 3. Critical cooling rate $\left(q_{\mathrm{cr}}\right)$ versus GS calculated using $T_{x}^{\mathrm{h}}$. GS parameters given by (a) Turnbull [22]; (b) Weinberg [24]; (c) Hrubÿ [18]; (d) Lu and Liu [25,26]; (e) $K_{1}$, Eq. (11); (f) $K_{2}$, Eq. (12) [18]; and (g) $K_{3}$, Eq. (13) [33]. Open symbols, dashed line: fine powder; closed symbols, full line: coarse powder. LB 2 $(\triangle) ; \mathrm{LS}_{2}(\bigcirc) ; \mathrm{CAS}_{2}(\triangle) ; \mathrm{M}_{2} \mathrm{~A}_{2} \mathrm{~S}_{5}(\square) ; \mathrm{NS}_{2}(\nabla) ; \mathrm{CMS}_{2}(\square)$; PS $(\diamond)$; and $\mathrm{G}($ 沈).

(the TTT or nose method), admitting the temperature at the nose $T_{\mathrm{n}} \sim\left(T_{\mathrm{m}}+T_{\mathrm{g}}\right) / 2$ and considering the time $t_{\mathrm{n}}$ to be inversely proportional to $u_{\max }$. The $q_{\mathrm{cr}}$ versus $u_{\max }$ dependence corroborates the very first proposal of Dietzel and Wickert [39] that considered glass crystallization on heating a process of crystal growth on athermal nuclei.

\subsection{Critical cooling rate calculations}

The present approach to calculate $q_{\mathrm{cr}}$ enables one to evaluate GFA controlled solely by heterogeneous surface crystallization, which is often predominant over crystallization originating from internal homogeneous nucleation, but $q_{\mathrm{cr}}$ depends on the square root of the nucleation site density, $N_{\mathrm{s}}^{1 / 2}$. In the case of pure homogeneous nucleation, there should be no difference in $q_{\mathrm{cr}}$ for bulk and powdered glasses. However, in most glasses, heterogeneous nucleation predominates over homogeneous nucleation and furthermore, when dealing with powdered samples, heterogeneous nucleation is enhanced by their higher specific surface. Thus, the consideration of only internal (homogeneous) nucleation to estimate $q_{\mathrm{cr}}$ should lead to much lower values than those obtained if one considers surface crystallization.
For instance, using the nose method and homogeneous nucleation and growth rate data, Cabral et al. [17] obtained $q_{\mathrm{cr}} \approx 0.2-0.3 \mathrm{~K} / \mathrm{s}$ for $\mathrm{LS}_{2}$. And the newest results of Cabral et al. [9] for $\mathrm{LS}_{2}$ glass, using the $\mathrm{CB}^{*}$ method, indicate $q_{\mathrm{cr}}=0.4 \mathrm{~K} / \mathrm{s}$. Havermans et al. [42] directly measured $q_{\mathrm{cr}}=3.6 \mathrm{~K} / \mathrm{s}$ by immerging in a crystallizing $\mathrm{LS}_{2}$ glass a $\mathrm{Pt}$ thermocouple. But $\mathrm{Pt}$ is a known nucleating agent for this composition, and thus the presence of some heterogeneous nucleation sites at the platinum-glass interface can explain the discrepant result from those of Refs. $[9,17]$. Ota et al. [19] measured the critical cooling rates of $\mathrm{LS}_{2}$ inspecting samples quenched at different cooling rates, by optical microscopy, looking for crystals on the surface as well as in the glass interior, and obtained the value of $1 \mathrm{~K} / \mathrm{s}$. Asayama et al. [43] determined a value close to $6 \mathrm{~K} / \mathrm{s}$ for the same composition, also by inspecting cooled samples by microscopy. All these former values indicate $q_{\mathrm{cr}}$ smaller than $7 \mathrm{~K} / \mathrm{s}$ for internal nucleation in $\mathrm{LS}_{2}$ glass. However, the present result ( $q_{\mathrm{cr}} \approx 71 \mathrm{~K} / \mathrm{s}$ ), assuming heterogeneous surface nucleation and $N_{\mathrm{s}}=10^{4} / \mathrm{m}^{2}$ for powdered $\mathrm{LS}_{2}$ glass, is much greater than that previously calculated values assuming homogeneous nucleation in bulk samples. Thus, a comparison of our results for $\mathrm{LS}_{2}$ with those of other authors confirm that surface 

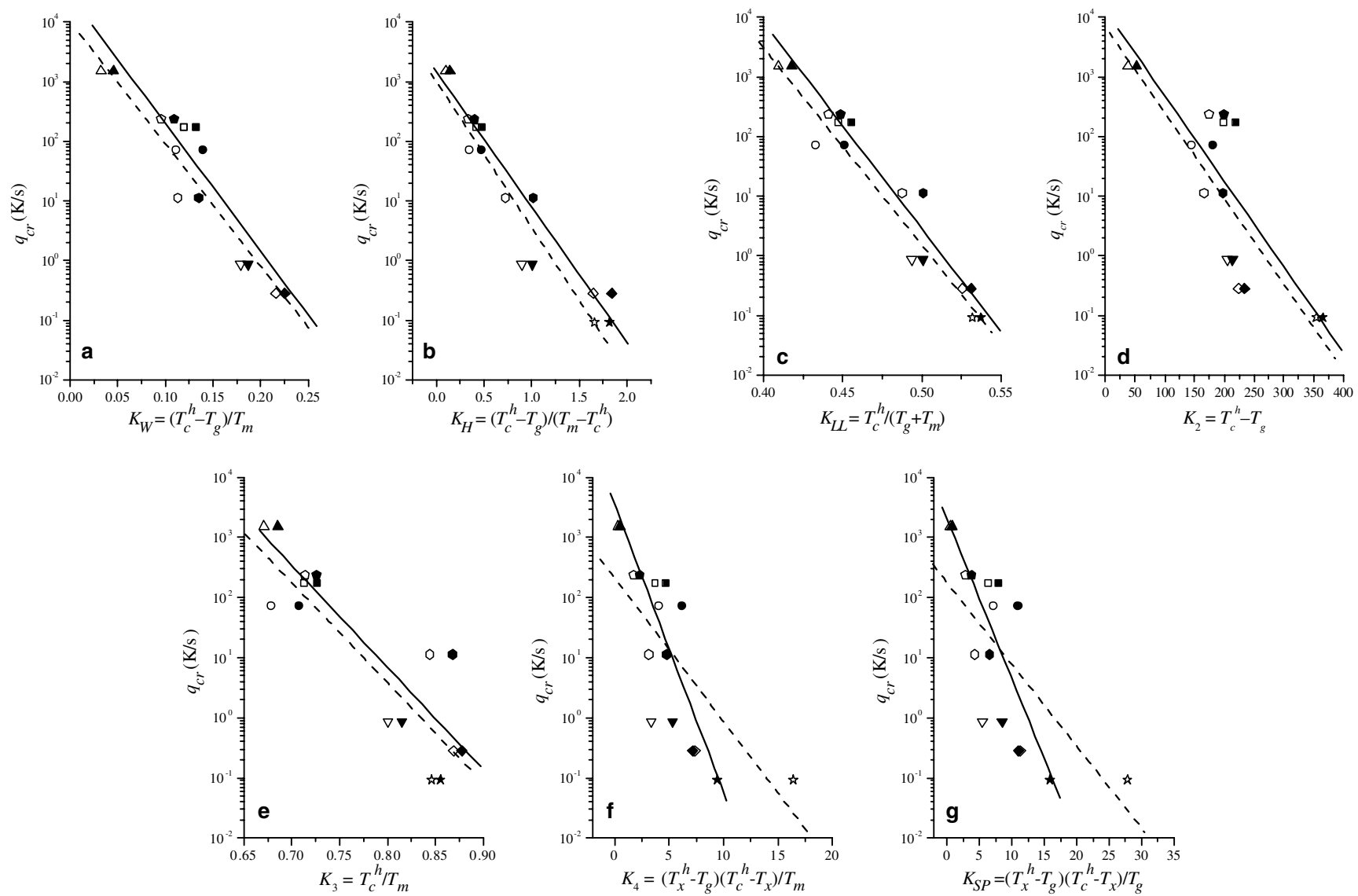

Fig. 4. Critical cooling rate $\left(q_{\mathrm{cr}}\right)$ versus GS calculated using $T_{\mathrm{c}}^{\mathrm{h}}$. GS parameters given by (a) Weinberg [24]; (b) Hrubÿ [18]; (c) Lu and Liu [25,26]; (d) $K_{2}$ [18]; (e) $K_{3}$, [33]; (f) $K_{4}$, [24]; and (g) $K_{\mathrm{SP}}$ [27]. Open symbols, dashed line: fine powder; closed symbols, full line: coarse powder. $\mathrm{LB}_{2}(\triangle)$; $\mathrm{LS}_{2}(\bigcirc)$; $\mathrm{CAS}_{2}(\sqcup)$; $\mathrm{M}_{2} \mathrm{~A}_{2} \mathrm{~S}_{5}(\square) ; \mathrm{NS}_{2}(\nabla) ; \mathrm{CMS}_{2}(\square) ; \mathrm{PS}(\diamond)$; and $\mathrm{G}($ 湤).

crystallization has a much stronger influence on GFA than internal nucleation, as we expected.

Now, looking at a glass that only shows surface crystallization in laboratory time scales, $\mathrm{NS}_{2}$, the measured critical cooling rates obtained by Ota et al. [19] were approximately $2 \times 10^{-3} \mathrm{~K} / \mathrm{s}$, while Havermans et al. [42] obtained $150 \times 10^{-3} \mathrm{~K} / \mathrm{s}$ with a Pt thermocouple inserted in the glass. And, finally, Asayama et al. [43] measured a $q_{\text {cr }}$ of approximately $4 \times 10^{-3} \mathrm{~K} / \mathrm{s}$. In this work we obtained $0.86 \mathrm{~K} / \mathrm{s}$ for the same system considering $\int_{T_{\mathrm{g}}}^{T_{\mathrm{m}}} u(T) \mathrm{d} T$ between $1.16 T_{\mathrm{g}}-T_{\mathrm{m}}$, in fact a too short temperature range. But, if we consider the $u_{\max } T_{\max } / 10$ or $u_{\max }\left(T_{\mathrm{m}}-T_{\mathrm{g}}\right) / 5$ approximations (that is, in the whole range from $T_{\mathrm{g}}$ to $\left.T_{\mathrm{m}}\right) q_{\mathrm{cr}}$ increases to $3.2 \mathrm{~K} / \mathrm{s}$ and $2.4 \mathrm{~K} /$ $\mathrm{s}$, respectively. Thus, once more, the critical cooling rates determined in this work are higher than those obtained by different methods, in a clear indication of the extreme sensitivity of $q_{\mathrm{cr}}$ to the (assumed or real) number of nucleation sites. Therefore, it should be stressed that the present calculations are only valid for glass powders having $N_{\mathrm{s}}=10^{4}$ sites $/ \mathrm{m}^{2}$.

Unfortunately the $q_{\text {cr }}$ calculated by Uhlmann $[3,44]$ and Cranmer et al. [45] using calculated TTT curves for silica, anorthite, $\mathrm{NS}_{2}$ and $\mathrm{GeO}_{2}$ cannot be used for comparisons with the present results because theoretical internal nucleation rates were assumed in these papers, which are many orders of magnitude below the experimental values for all glasses known so far. Additionally these glasses do not reveal volume nucleation.

But, despite the approximation of constant $N_{\mathrm{s}}$, the present results show that our current analysis, which considers only heterogeneous surface nucleation, allows one to classify the present glasses. The resulting GFA decreases in the following sequence: $\mathrm{LB}_{2}, \mathrm{CAS}_{2}, \mathrm{CMS}_{2}, \mathrm{LS}_{2}, \mathrm{M}_{2} \mathrm{~A}_{2} \mathrm{~S}_{5}$, $\mathrm{NS}_{2}$, PS e G. Thus, according to these results, compositions G, PS and $\mathrm{NS}_{2}$ are the easiest to vitrify on cooling, while $\mathrm{LB}_{2}$ is the most difficult to be obtained as a glass, and indeed, these findings agree with our practice in laboratory observations of glass formation during melting and quenching these glasses.

\subsection{Critical cooling rates versus stability parameters}

Figs. 3 and 4 comprise a range of almost four orders of magnitude in $q_{\mathrm{cr}}\left(0.1 \mathrm{~K} / \mathrm{s}<q_{\mathrm{cr}}<1500 \mathrm{~K} / \mathrm{s}\right)$, and indicate that $q_{\mathrm{cr}}$ correlates well with some GS parameters. Only the parameters $K_{\mathrm{T}}$ and $K_{1}$ do not present a smooth relationship with $\log q_{\mathrm{cr}}$ among the fourteen GS tested. For 
$K_{\mathrm{W}}, K_{\mathrm{H}}, K_{\mathrm{LL}}, K_{\mathrm{SP}}, K_{2}, K_{3}$, and $K_{4}$, the higher the GS the lower the $q_{\mathrm{cr}}$, and there is approximately a linear relationship between $\log q_{\text {cr }}$ and the respective GS parameter. A linear relationship shows up in the graphs, but we do not intent to impede the possibility of other types of mathematical relationships between GS and $\log q_{\mathrm{cr}}$. We thus take the most obvious linear relationship only to compare the present data and show that a relationship exists in some cases without caring to establish the most precise one.

Table 6 presents results of linear relationships of the type $\log q_{\mathrm{cr}}=C+D K$, where $C$ and $D$ are constants and $K$ is the GS parameter utilized, together with the corresponding correlation factor $R^{2}$ of curves presented in Figs. 3 and 4 . The best GS are $K_{\mathrm{W}}, K_{\mathrm{H}}$ and $K_{\mathrm{LL}}$, which present the highest $R^{2}$ values, $(>0.90) . K_{\mathrm{LL}}$ with $T_{\mathrm{c}}^{\mathrm{h}}$ produced the best correlation $\left(R^{2}=0.97\right)$. No obvious correlations were found for the parameters $K_{\mathrm{T}}$ and $K_{1}$.

The Hruby parameter, $K_{\mathrm{H}}$, and $K_{2}$ are the most sensitive to $q_{\mathrm{cr}}$, varying from 0 to 2 and 50 to $400{ }^{\circ} \mathrm{C}$, for the studied glasses, while $K_{\mathrm{W}}$ only varies between 0.00 and 0.25 ; and $K_{\mathrm{LL}}$ only varies between 0.40 and 0.55 for the same glasses.

In general, using $T_{x}^{\mathrm{h}}$ instead of $T_{\mathrm{c}}^{\mathrm{h}}$ produces somewhat better regression results, which are most significant for the GS parameters $K_{\mathrm{LL}}$ and $K_{3}$. Changing from coarse to fine powders leads to very small changes. All fine powders resulted in systematically lower correlation parameters for $\log q_{\text {cr }}=C+D K$, but it is possible to argue that the relative small difference in grain size between fine and coarse samples $(22-38 \mu \mathrm{m}$ and $150-177 \mu \mathrm{m}$, respectively) is not significant to produce strong differences in the DSC peaks.

The $K_{4}$ and $K_{\mathrm{SP}}$ parameters show low correlation factors with $\log q_{\mathrm{cr}}$. They are similar and the discrepancy between the fine and coarse powders shown in Fig. 4 and Table 6 is remarkable.

According to Hrubÿ [18], a glass with a short interval $T_{x}^{\mathrm{h}}-T_{\mathrm{g}}$ exhibits a high crystallization tendency, which is unfavorable to glass formation. On the other hand, a short temperature interval $T_{\mathrm{m}}-T_{x}^{\mathrm{h}}$ indicates that the crystalline phase formed at $T_{x}^{\mathrm{h}}$ is ready to melt, which is favorable to glass formation. In summary, following Hrubÿ's ideas: (i) all glasses are in comparable states at $T_{\mathrm{g}}$; (ii) the interval $T_{x}^{\mathrm{h}}-T_{\mathrm{g}}$ is directly proportional to GFA; (iii) the interval
$T_{\mathrm{m}}-T_{x}^{\mathrm{h}}$ is inversely proportional to GFA. It is known that alone $T_{\mathrm{g}}$ is not sufficient to classify materials according to their glass forming ability. One can observe, using values from Tables 3 and 5, that $\log q_{\text {cr }}$ does not correlate with $T_{\mathrm{m}}-T_{x}^{\mathrm{h}}$, while $K_{2}=T_{x}^{\mathrm{h}}-T_{\mathrm{g}}$ is somewhat correlated with $q_{\mathrm{cr}}$, as verified from Figs. 3(f) and 4(d). However, the parameter of Hrubÿ, $K_{\mathrm{H}}=\left(T_{x}^{\mathrm{h}}-T_{\mathrm{g}}\right) /\left(T_{\mathrm{m}}-T_{x}^{\mathrm{h}}\right)$, shows a good correlation with $q_{\mathrm{cr}}$ in $\log$ scale. This same discussion is valid if one uses $T_{\mathrm{c}}^{\mathrm{h}}$ instead of $T_{x}^{\mathrm{h}}$.

$\mathrm{Lu}$ and Liu $[25,26]$ also proposed a linear correlation between the logarithm of the cooling rates and their GS $\left(K_{L L}\right)$ for various oxide glass-forming systems. They found that the GFA was expressed by the empirical relation $\log q_{\mathrm{cr}}=24.4-33.1 K_{\mathrm{LL}}\left(R^{2}=0.8\right)$ (following our notation). Their result is very similar to ours (using $T_{x}^{\mathrm{h}}$ or $T_{\mathrm{c}}^{\mathrm{h}}$, considering fine and coarse samples), but with a different intercept, probably due to the approximated literature values of $q_{\mathrm{cr}}$ used. A weak correlation $\left(R^{2}=0.73\right)$ between $\log q_{\mathrm{cr}}$ and $K_{\mathrm{T}}$ was found in the work of $\mathrm{Lu}$ and Liu for metallic glasses [25], and a very poor correlation $\left(R^{2}=0.4\right)$ was found for cryoprotective agents [26].

Eq. (4) and results of Table 4 for the integral show that $q_{\mathrm{cr}}$ is proportional to $u_{\max }$. In addition, Fokin et al. [40,41] demonstrated that glasses with the highest $u_{\max }$ have the lowest $T_{\mathrm{g}} / T_{\mathrm{m}}$. More specifically, those authors showed that $u_{\max }$ decreases with $T_{\mathrm{g}} / T_{\mathrm{m}}$. As $u_{\max }$ and $q_{\mathrm{cr}}$ are proportional, this finding supports a correlation between GFA and the GS, as proposed by Turnbull's $K_{\mathrm{T}}$. However, according our results shown in Fig. 3(a) there is no direct relationship between $\log q_{\mathrm{cr}}$ and $K_{\mathrm{T}}$. Some reasons for only a weak correlation between these parameters are the following [46]: crystallization occurs during cooling at a temperature close to $T_{\max }$, while during heating it occurs at $T_{\mathrm{c}}^{\mathrm{h}}$. $u_{\max }$ (and $T_{\max }$ ) correlates with $T_{\mathrm{g}} / T_{\mathrm{m}}$ (but that correlation is not so strong), and the existence of any correlation between $T_{\mathrm{c}}^{\mathrm{h}}$ and $T_{\mathrm{g}} / T_{\mathrm{m}}$ is questionable. Thus, parameters including both $T_{\mathrm{g}} / T_{\mathrm{m}}$ and $T_{\mathrm{c}}^{\mathrm{h}}$ better describe GFA than parameters that only include the $T_{\mathrm{g}} / T_{\mathrm{m}}$ ratio, such as $K_{\mathrm{T}}$.

A detailed look at Eqs. (5)-(13) shows some peculiarities: twelve parameters are proportional to $T_{x}^{\mathrm{h}}\left(\right.$ or $\left.T_{\mathrm{c}}^{\mathrm{h}}\right)$. Specifically, $K_{\mathrm{W}}, K_{\mathrm{SP}}, K_{4}$ and $K_{\mathrm{H}}$ are proportional to $T_{x}^{\mathrm{h}}-T_{\mathrm{g}}$. $K_{\mathrm{T}}$ and $K_{1}$ are the only ones that do not present good linear

Table 6

Linear fittings of $\log q_{\mathrm{cr}}=C+D K$, where $C$ and $D$ are constants, $K$ is the GS parameter utilized and $R^{2}$ is the corresponding correlation factor of some curves presented in Figs. 3 and 4

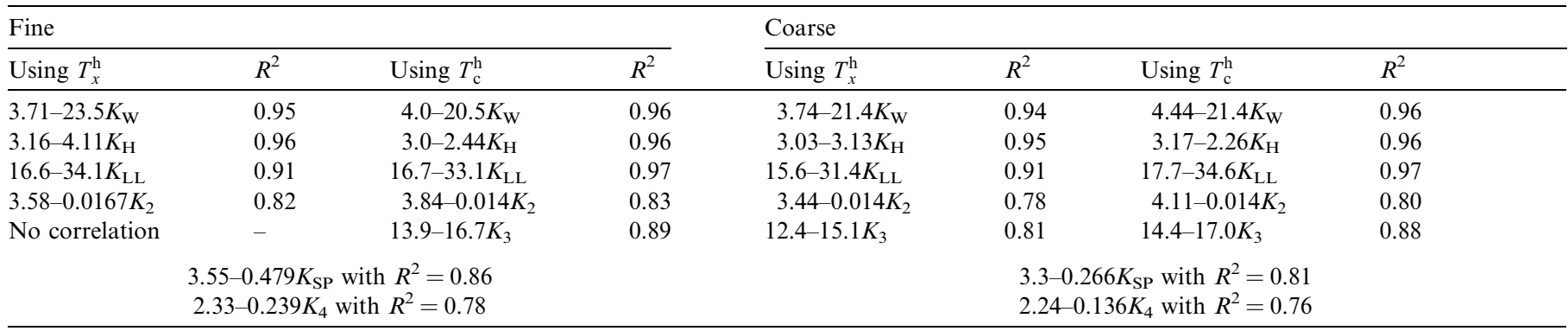

The parameters $K_{\mathrm{T}}$ and $K_{1}$ are not shown in this table. 
(in $\log$ scale for $q_{\mathrm{cr}}$ ) correlation with GFA, and include only $T_{\mathrm{g}}$ and $T_{\mathrm{m}}$. It is thus clear that the best relationships between GFA and GS are provided by GS parameters that include three characteristic temperatures, such as the parameters of Weinberg, Hrubÿ, and Lu and Liu. All these GS parameters include $T_{x}^{\mathrm{h}}\left(\right.$ or $\left.T_{\mathrm{c}}^{\mathrm{h}}\right), T_{\mathrm{g}}$ and $T_{\mathrm{m}}$. From a general point of view our results prove that GFA can be estimated by some GS parameters for glasses that nucleate mainly heterogeneously.

\section{Conclusions}

We calculated the critical cooling rates for eight glass forming compositions - for which heterogeneous nucleation predominates - using the JMAK equation, the most likely number of surface nucleation sites and experimental crystal growth rate data. The $q_{\mathrm{cr}}$ were consistent with experimental observations on melting and quenching these eight glasses in the laboratory. The calculated $q_{\mathrm{cr}}$ consistently varied with glass composition, indicating that the method proposed in this paper can be used to estimate the relative glass forming ability of different glasses that exhibit predominant surface nucleation.

For lithium disilicate glass (which also exhibits internal nucleation), the critical cooling rates considering only internal homogeneous nucleation were one or two orders of magnitude smaller than those estimated for surface heterogeneous crystallization. Therefore, surface crystallization controls GFA, as we predicted.

Glass stability parameters were evaluated by fourteen different methods. From these, twelve parameters, specifically those that involved the crystallization peak, $T_{x}^{\mathrm{h}}$ or $T_{\mathrm{c}}^{\mathrm{h}}$, show relatively good empirical correlations with GFA. However, the best correlations were found for those GS parameters that involved at least three DSC characteristic temperatures $\left(T_{x}^{\mathrm{h}}\right.$ or $T_{\mathrm{c}}^{\mathrm{h}}, T_{\mathrm{g}}$ and $\left.T_{\mathrm{m}}\right)$. Our results demonstrate that GFA and some GS parameters are indeed correlated. There were no noteworthy differences for fine or coarse grains. The alternative use of $T_{\mathrm{c}}^{\mathrm{h}}$ instead of $T_{x}^{\mathrm{h}}$ in some expressions did not result in significant differences in the GS parameters.

The overall results of this research indicate that the GS parameters $K_{\mathrm{W}}, K_{\mathrm{H}}$ and $K_{\mathrm{LL}}$, which are easy to measure, can be used to compare the relative vitrification tendency of different oxide glass-forming systems. These relationships between GS parameters and $q_{\mathrm{cr}}$ are valid for glasses that show predominant heterogeneous nucleation in laboratory time scales.

\section{Acknowledgements}

We acknowledge FAPESP, CAPES and CNPq (Brazil) for funding this research. The motivation arouse from the CIAM - Inter American Cooperation Program on Materials - funded by the NSF/CNPq/CONICET, which involves the University of Missouri, Rolla (USA), the Federal University of São Carlos (Brazil), and the Centro Atómico
Bariloche (Argentine). Special thanks are due to Dr Vladimir Fokin (State Optical Vavilov Institute, Russia) for his useful comments, to Drs Ana C.M. Rodrigues (Federal University of São Carlos, Brazil), Ralf Keding (Otto Schott Institute, Germany) and Ralf Müller (Federal Institute for Materials Research and Testing, Germany) from providing some samples to us.

\section{References}

[1] I. Gutzow, J. Schmelzer, The Vitreous State - Thermodynamics, Structure, Rheology, and Crystallization, Springer-Verlag, Berlin, 1995.

[2] I. Avramov, E.D. Zanotto, M.O. Prado, J. Non-Cryst. Solids 320 (2003) 9.

[3] D.R. Uhlmann, J. Non-Cryst. Solids 7 (1972) 337.

[4] W. Huang, C.S. Ray, D.E. Day, J. Non-Cryst. Solids 86 (1986) 204.

[5] J. Colmenero, J.M. Barandiarán, J. Non-Cryst. Solids 46 (1981) 277.

[6] G. Whichard, D.E. Day, J. Non-Cryst. Solids 66 (1984) 477.

[7] C.S. Ray, D.E. Day, J. Am. Ceram. Soc. 67 (1984) 806.

[8] C.S. Ray, D.E. Day, J. Non-Cryst. Solids 81 (1986) 173.

[9] A.A. Cabral, A.A.D. Cardoso, E.D. Zanotto, J. Non-Cryst. Solids 320 (2003) 1.

[10] C.S. Ray, S.T. Reis, R.K. Brow, W. Höland, V. Rheinberger, J. NonCryst. Solids 351 (2005) 1350

[11] I. Gutzow, I. Avramov, K. Kästner, J. Non-Cryst. Solids 123 (1990) 97.

[12] W.A. Johnson, R.F. Mehl, Trans. AIME 135 (1939) 416.

[13] M. Avrami, J. Chem. Phys. 7 (1939) 1103

[14] M. Avrami, J. Chem. Phys. 8 (1940) 212.

[15] M. Avrami, J. Chem. Phys. 9 (1941) 177.

[16] A. Kolmogorov, Izv. Acad. Sci. URSS Ser. Math. 1 (1937) 355.

[17] A.A. Cabral, C. Fredericci, E.D. Zanotto, J. Non-Cryst. Solids 219 (1997) 182

[18] A. Hrubÿ, Czech J. Phys. B 22 (1972) 1187.

[19] R. Ota, T. Wakasugi, W. Kawamura, B. Tuchiya, J. Fukunaga, J. Non-Cryst. Solids 188 (1995) 136.

[20] M.L.F. Nascimento, PhD thesis, Federal University of São Carlos, 2004 (in Portuguese)

[21] R. Müller, J. Non-Cryst. Solids 219 (1997) 110.

[22] D. Turnbull, Contem. Phys. 10 (1969) 473.

[23] W. Kauzmann, Chem. Rev. 43 (1948) 219.

[24] M.C. Weinberg, Phys. Chem. Glasses 35 (1994) 119.

[25] Z.P. Lu, C.T. Liu, Acta Mater. 50 (2002) 3501.

[26] Z.P. Lu, C.T. Liu, Phys. Rev. Lett. 91 (2003) 115505

[27] M. Saad, M. Poulain, Mater. Sci. Forum 19\&20 (1987) 11.

[28] D.C. Tran, R.J. Ginther, G.H. Sigel, Mater. Res. Bull. 17 (1982) 1177.

[29] C.A. Angell, 2nd Int. Symp. Halide Glasses, Troy, New York (1983).

[30] M.G. Drexhage, O.H. El-Bayoumi, H. Lipson, C.T. Moynihan, A.J. Bruce, J. Lucas, G. Fonteneau, J. Non-Cryst. Solids 56 (1983) 51.

[31] R.M. Almeida, J.D. Mackenzie, Glastechn. Ber. 56K (1983) 850.

[32] E.I. Cooper, C.A. Angell, J. Non-Cryst. Solids 56 (1983) 75.

[33] T. Wakasugi, R. Ota, J. Fukunaga, J. Am. Ceram. Soc. 75 (1992) 29.

[34] R.-G. Duan, K.-M. Liang, S.-R. Gu, J. Euro. Ceram. Soc. 18 (1998) 1131.

[35] M.C. Weinberg, J. Non-Cryst. Solids 167 (1994) 81.

[36] R. Müller, E.D. Zanotto, V.M. Fokin, J. Non-Cryst. Solids 274 (2000) 208.

[37] L.W. Herron, C.G. Bergeron, Phys. Chem. Glasses 19 (1978) 89.

[38] S. Reinsch, R. Müller, M.L.F. Nascimento, E.D. Zanotto, Proceedings XX International Conference on Glass, Kyoto, 2004.

[39] A. Dietzel, H. Wickert, Glastech. Ber. 29 (1956) 1.

[40] V.M. Fokin, M.L.F. Nascimento, E.D. Zanotto, J. Non-Cryst. Solids 351 (2005) 789 
[41] E.D. Zanotto, V.M. Fokin, Phil. Trans. Roy. Soc. Lond. A 361 (2003) 591.

[42] A.C.J. Havermans, H.N. Stein, J.M. Stevels, J. Non-Cryst. Solids 5 (1970) 66.

[43] E. Asayama, H. Takebe, K. Morinaga, ISIJ Int. 33 (1993) 233.
[44] D.R. Uhlmann, in: A.R. Cooper, A.H. Hewer (Eds.), Mass Transport Phenomena in Ceramics, Materials Science Research vol. 9 (1975) 465.

[45] D. Cranmer, R. Salomaa, H. Yinnon, D.R. Uhlmann, J. Non-Cryst. Solids 45 (1981) 127.

[46] V.M. Fokin, private communication, 2005. 